\title{
Using Relational Database Model in Cloud Computing
}

\author{
Loredana Mocean*, Vasile Paul Bresfelean* \\ *(Babes-Bolyai University of Cluj-Napoca, Romania) \\ Email: Ioredana.mocean@econ.ubbcluj.ro, paul.bresfelean@econ.ubbcluj.ro)
}

\begin{abstract}
The advent of digital systems for the production and trans mission of information decisivelyinfluences human progress and represents the future in any field of social life. In order to survive, organizations must correlate the obj ectives to the new trend of the society based on information, deeply marked by globalization. In recent years new computational paradigm were proposed and adopted. These include Cloud computing. Together with the stabilization of technologies related to Cloud computing, SQL databases have become more attractive due to native support for scalability and distributed architecture and the fact that many of these can be offered as services. The paper presents a few important aspects about cloud computing and proposed a new database designed to be implemented in cloud. We offer a new model and an example of implementing in Romanian medicine ${ }^{1 .}$
\end{abstract}

\section{Keywords}

Distributed computing services, Cloud computing, database, query, SQL

\section{INTRODUCTION}

Cloud computing is a modern concept in computing and informatics, representing overall dis tributed computing services, applications, access to information and data storage with out the user needing to know the location and physicalconfiguration of systems providing these services [1]. It was defined by the National Institute of Standards and Technology (NIST) and we can say that Cloud computing is a suitable model to allow acces s to application-based network to a group of configurable computing resources (e.g. networks, servers, storage, applications and services) that can be available to the user quickly and with minimal management effort or interaction with the provider of thes e services [16]. Synthesizing what we mean by Computing: the design and development of hardware and software systems, processing, structuring and management of information, creating scientific studies using computer, adding intelligence in computational s ys tems, creating and using communication or multimedia environments.

The permanent connection to the Internet became widespread, so almost all available resources can be placed on theWeb and shared sometimes even between users completelyindependent from each other: software and data/information are brought from Internet to the user's computer on demand, as if they were ordinary public services like water or electricity. The execution of computer applications online on the Internet, and not on the workstation, represents a new change of paradigm, descendant of the 1980s, when it switched from mainframes to a client-server concept. If the interface provided by the cloud computing supplier (provider) has a good quality, then the user is freed from the task of being an expert in the utilized technologyand infrastructure. For example, a user does nothave to update the software because it is made by the provider.

Cloud computing uses new methods of providing and consuming IT services on Internet, services that usually can be dynamically sized and include virtualized resources. It is reallyjust a secondarypossibility, due to the ease with which they can now access all servers and data centers interconnected through the Internet.

Typical cloud computing providers make available, for example, standard commercial applications; only the us erhas access to them through a local browser, since both the application and the user's own data are hosted in cloud, on the provider's service server.

Starting from these considerations, the article has a structure presented in the following paragraph. Section 1 includes the Introduction. In section 2 we offer a literature review and key achievements of our research. Section 3 contains a new architecture proposal of a database and the cloud extension and Section 4 presents some aspects about querying data. The paper ends with the conclusions section.

\section{PROBLEM STATEMENT AND BACKGROUND}

\section{An overview in Cloud computing}

Among the clienteles of cloud computing we can mention mobile devices, terminals or usual computers. Some ofits benefits are the minor hardware costs, lower IT costs, security, lower power consum ption, easy repair and replacement, low noise. Data centers can be collections of servers in which subscription applications are hosted. Theycan be based on a large hall in the same building or on a room of servers outside the organization. Virtualized servers allow software to be installed allowing multiple instances of virtual servers that can be operated. Another feature would be that a lot of virtual servers can run on one physical server. In case of distributed servers, the servers must not be located all in the same location, theyca $n$ be placed in separate geographic locations. If something happens to a site, such as a power failure, the service can be accessed from another site.

\footnotetext{
${ }^{1}$ This is an extended paper of the article presented at The 15th International Conference on Informatics in Economy, ClujNapoca, 2016.
} 
As we know from the cloud literature [1][2], there are four important types of clouds:

- Private, owned or leased by a single organization and operated only by that organization

- Communityshared by several organizations and supports a specific community that shares the same themes (e.g. considerations of mission, security requirements, policy, etc.)

- Public, owned by an organization that sells services to the general public or a large industrial group

- Hybrid, a composite of two or more clouds (internal, community, or public) that remain unique entities but arebundled together by standardized technologies or an owner who allows portability of data and applications (for example to survive some peaks of usage, see figure 1).

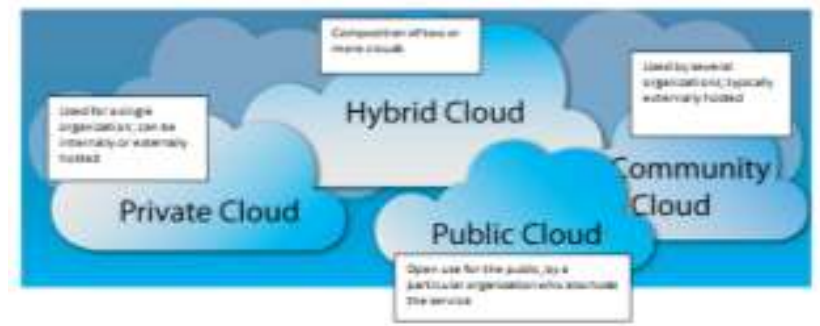

Fig. 1. Types of clouds

By using the modern, intuitive, and powerful databases built on a cloud platform, much of the development process will be managed: security, authentication, database interactions, input validation, sessi on state management and many others [9]. All the tools we need are available in a single, extensible database, due to classification and models of Cloud computing technology, as we see: the model of service delivery or deploymentmodel.

Cloud computing services are offered to customers in three modes of implementation: private, public and hybrid. The private cloud model (or internal) has as user for instance a company. There can be represented several different departments within the same company. They are using virtualization on the existing servers in the company to improve the use of workstations. A private cloud also involves supplying and measurement of the components, enabling rapid deployment and change components if necessary.

The public cloud (or external) is basically the provision of resources through the Internet for many users simultaneously. Customers share in this way the applications, power processing and

Major advantages of Cloud computing just emerge from the basic idea of this technology: regardless of location, personal or company, data is accessed via the Internet with absolutely any equipment that allows web surfing (regardless of its hardware performance). Using these services involves giving up own IT infrastructure and renting storage and processing systems, as well as investment to access various applications through the Internet, which are traditionally stored on individual computers.

The cloud computing applications are actually available on the web in a big number. There are many providers with their own design where users can obtain qualitycloud services. We can easily use the data storages in cloud with the Internet connections.

These are two important as pects we must see: Cloud computing applications for easycommunication and Cloudcomputing applications for easy data storages (see figure 2). We can easily save the documents on the cloud, get those documents and share them with other users, put the files on the cloud, get data from there. All of these with cheap costing.

There are other examples like the YouTube, Soundcloud, etc. that really are useful as the media services.

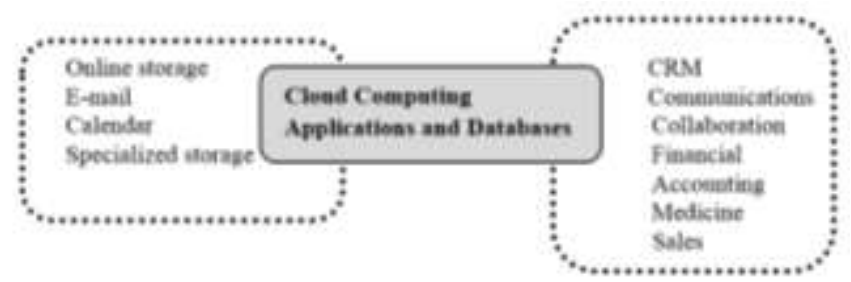

Fig.2. Cloud Computing applications and databases

Cloud computing applications, are the cloud-based services also known as Software as a Service (SaaS), as we mentioned before. These applications can do everything from keeping track of notes to accounting [3][4]. SaaS allows companies to ensure all users that their application is on the same software version. This is because theycan provide automatic updates to cloud applications, rather than waiting for users to do it themselves. This also helps with support, as the companywill know what version of the software is being used when issues are logged.

Another good parts of these applications are everyone benefits : cloud apps allow companies to push new developments to all users at once, ensuring everyone benefits at the same time [18]. 
Some of important ten Cloud applications are: Mozy - mozy.co.uk, Skype - skype.com, Box - Box.com, Toggl - toggl.com, Moo - uk.moo.com, MailChimp - mailchimp.com, Quickbooks - quickbooks.intuit.co.uk, Evernote - evernote.com, Google Apps for Business - google.com, Outright - outright.com [5].

Afew of the databases used in Cloud computing are :Big Data, Amazon Web Services, EnterpriseDB (focuses on the open source PostgreSQL databases, it is able to work with Oracle database applications), Garantia Data (offers a gatewaysenice for users to run open source Redis and Memcached in-memory NoSQL databases), Google Cloud SQL, Microsoft Azure [6].

Microsoft solution for cloud computing is Windows Azure (https://azure.microsoft.com/en-us/). This is a complete set of services that enables the development, hosting and scaling of the applications in Micros oft datacenters. To crea te a Cloud Computing application, one must go through the following steps [7][8]:

- Understand Cloud Computing, laaS, PaaS, SaaS

- Construction of applications based on cloud, scalable, fault-tolerant and secure, using Windows Azure platform

- Using existing knowledge of .NET and Visual Studio to develop applications for Cloud using services provided by Windows Azure

- $\quad$ Creating, implementing and configuring ASP.NET applications running in Windows Azure platform

- Hosting Windows Communication Foundation (WCF) services using WA

- The use of queues and worker roles for asynchronous processing

- $\quad$ Creating and accessing SQL Azure databases for storing data in the cloud

- Using Azure Service Bus services and Access Control for looselycoupled application development .

\section{State of the art}

Building a database cloud application can be a challenge for any researcher and programmer. As we can find in paper [10], there are three major components of Database Schema Service: a platform to quickly develop and deploy applications, a set of easily installed built-in packaged applications, and the ability to conveniently access data using restful web services.

We can create web applications that share data using only a web browser and needing only limited programming experience. We can deploy applications, manage users and application security by configuring application authentication and authorization access options [9].

When we think to create a database for cloud we must think that cloud computing uses a network of computers to provide services that otherwise would be provided by a single computer or computer server [10].

The authors of paper [11] state that the cloud computer databases have a set of key benefits: simplicity - in provisioning, development, deployment and pricing, portability - to any platform that supports the DBMS, in a public or private cloud, enterprise strength - through the power of implemented technologyand productivity - for your IT staff and business users.

David Linthicum in his study [12] states that the data processing requirements of cloud computing is causing many to leave $\mathrm{SQL}$ and relational databases behind and try to use a new technology and the cloud changes everything.

Saeid Abolfazli et al. in their paper [13] survey the augmentation domain and presents taxonomy of new databases approaches. The objectives of the study is to highlight the effects of remote resources on the quality and reliability of augmentation processes and discuss the challenges and opportunities of introducing the cloud-based resources in augmenting new cloud computing technology.

In paper [14], the authors take into consideration on-line Transaction Processing (OLTP) applications, model twoincremental repartitioning algorithm and lookup mechanism and develop a unique transaction generation model for simulation.

J. Kamal et al. in their paper explain that cloud applications often relyon distributed databases that can sustain rapid growth in data volume. Distributed transactions that involve data tuples from multiple servers can adverselyimpact the performance of such databases, especially when the transactions are short-lived in and require immediate response [15].

In paper [22], Gelogo and Lee underline the idea that in the last years the number of outsourcing database will grow significantly and Database Management Systems as a cloud service will offer less expensive platform for development.

Starting from the existing literature in the field, paper aims to present a viewpoint on creating the databases belonging medicine with the applicability in Cloud. The operation aims to increase the functionality and reliability of the introduction and retrieval of data and the ability to provide user access physician or patient unit, aggregate data of interest to both.

An easy way to comply with the conference paper formatting requirements is to use this document as a template and simply type your text into it.

\section{CASE STUDY. DESIGNING A DATABASE FOR THE CLOUD.}

According to [8] "a cloud database is a database accessible to clients from the cloud and delivered to users on demand via the Internet from a cloud database provider's servers". The database is transformed, optimized and built for a virtualized 
computing environment [19]. A cloud database can be a traditional database such as a MySQL or SQL Server database and also can be a native cloud

database tends to better equipped to optimallyuse cloud resources and to guarantee scalability [8].

Security and privacy, and the potential loss of or inability to access critical data in the event of a disaster or bankruptcy of the cloud database service provider must be taken into consideration[8]. In the same time ensuring security and privacy for data management and query processing in the cloud is critical for uses of the cloud [20].

The following application shows the computerization of business management of a medical office.

The web application automates electronic medical patients list and all activities undertaken by staff of the cabinet. It offers the possibility to track the route of a patient starting from entering the system, schedule a consultation, filling in the consultation sheet and up to the management of the medical documents issued in time for the patient. It begins database design using the following steps.

\begin{tabular}{|c|c|}
\hline No & Attribute \\
\hline 1 & Doctor's name \\
\hline 2 & Doctor's surname \\
\hline 3 & Doctor's ID \\
\hline 4 & Mobile phone \\
\hline 5 & E-mail \\
\hline 6 & Title ID \\
\hline 7 & Coordinator's ID \\
\hline 8 & Employment date \\
\hline 9 & Statute \\
\hline 10 & Title \\
\hline 11 & Base salary \\
\hline 12 & Work experience \\
\hline 13 & Advance on salary \\
\hline 14 & Total salary \\
\hline 15 & Bonus for work experience \\
\hline 16 & Patient's first name \\
\hline 16 & Patient's last name \\
\hline 17 & $\operatorname{Sex}$ \\
\hline 18 & SSN \\
\hline 19 & Hall number \\
\hline
\end{tabular}

\begin{tabular}{|l|l|}
\hline 20 & Chronic diseases \\
\hline 21 & Treatment \\
\hline 22 & Health condition \\
\hline 23 & Improved \\
\hline 24 & Days \\
\hline 25 & Id treatment \\
\hline 26 & Diagnosis \\
\hline 27 & Pills \\
\hline 28 & Program \\
\hline 29 & Assistant's ID \\
\hline 30 & Day 1 \\
\hline 31 & Schedule1 \\
\hline 32 & Day2 \\
\hline 33 & Schedule2 \\
\hline 34 & Specific room \\
\hline 35 & Floor \\
\hline 36 & Interior \\
\hline 37 & No. beds \\
\hline 38 & Hall dimension \\
\hline
\end{tabular}

Fig.3. The attributes of our database.

\section{Identifying the attributes stored in the database and the management rules}

One of the most important applications for computers is storing and managing information in cloud. The manner in which information is structured and presented can have an important effect on how easy is to access and manipulate.

We must respect all the steps in designing a relational database in order to obtain a complexdatabase which can be used in cloud.

According $1 \mathrm{NF}$ it will decompose composite attributes, eliminating also derived attributes. In our case the total salary. It follows therefore Dictionary table in first normal form (see figure 3 ).

Dictionary (Doctor's name, Doctor's surname, Id_doctor, Mobile phone, E-mail, Id_title, Id_coordonator, Employment date, Statute, Title, Base salary, Work experience, Advance on salary, Total salary, Bonus for work experience, Patient's name, Patience's surname, Sex, CNP, Hall's number, Chronic diseases, Treatment, Health condition, Im proved, Days, Idtreatment, Diagnosis, Pills, Program, Id_asistent, Day 1, Schedule1, Day2, Schedule2, Specific room, Floor, Interior, Nr. beds, Hall dimension). 
I NTERNATIONAL JOURNAL OF COMPUTERS \& TECHNOLOGY

An important issue when we use the relational data model is how we select an appropriate database scheme. As management rules we have:

1. Doctor can handle more patients

2. In a room maybe several treatments.

The next step would be to identify the role of primary key attributes : Id_doctor, Id_title , Id_asistent, Hall nr., CNP , Id_treatment. Diagram of the database structure (figure 4) is presented below.

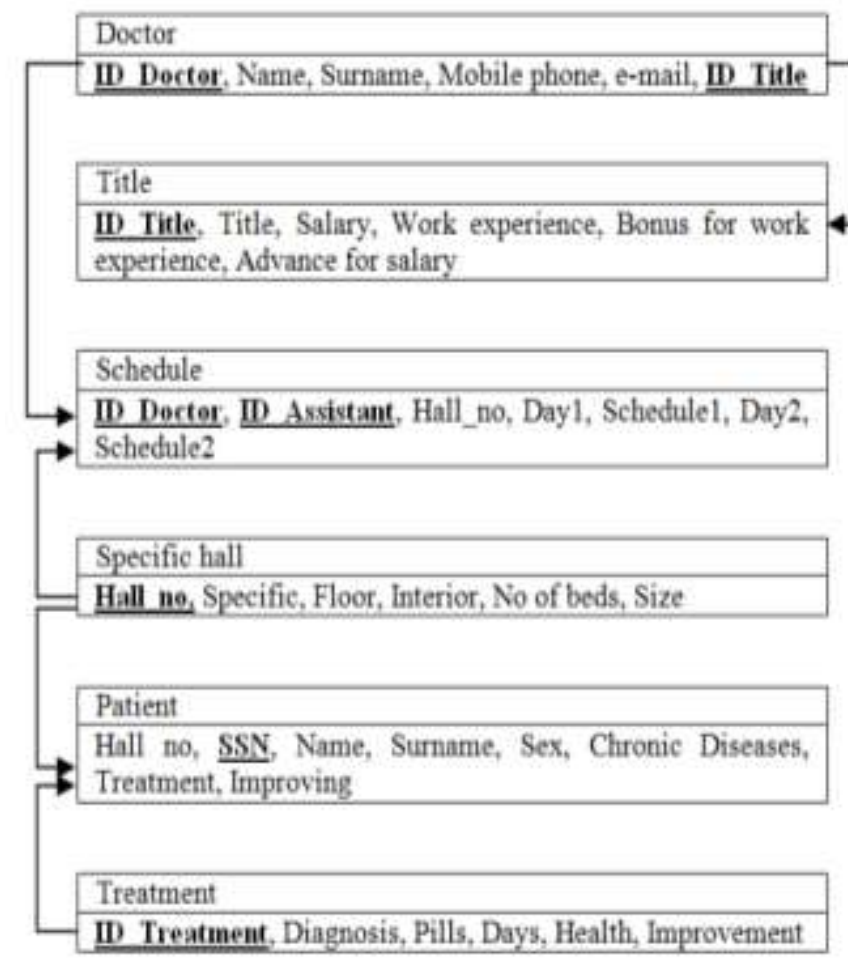

Fig. 4. Diagram of the structure of the database

\section{Defining tables and integrity constraints}

The simplest butmost versatile way to organize information is to store it in tables. After that we can transfer them in clou d. The tables must be powerful and flexible and the simplest way to represent information in cloud.

\section{The Doctor's Table}

\begin{tabular}{|l|l|l|l|l|}
\hline Attribute & Type & Unique & $\begin{array}{l}\text { Re - } \\
\text { quired }\end{array}$ & $\begin{array}{l}\text { Referential } \\
\text { Integrity }\end{array}$ \\
\hline Doctor_first name & Short Text & & & \\
\hline Doctor_lastname & Short Text & & & \\
\hline ID_Doctor & Number & Yes & Yes & Yes \\
\hline Mobile phone & Short Text & & & \\
\hline E-mail & Short Text & & & \\
\hline Id_Title & Number & & & Yes \\
\hline Id_Coordinator & Number & & No & \\
\hline Employment day & Date/Time & & No & \\
\hline Statute & Number & & No & \\
\hline
\end{tabular}


The TITLE table

\begin{tabular}{|l|l|l|l|}
\hline Attribute & Type & Unique & $\begin{array}{c}\text { Referential } \\
\text { Integrity }\end{array}$ \\
\hline Id_Title & Number & Yes & Yes \\
\hline Title & Short Text & & \\
\hline Salary & Number & & \\
\hline Work experience & Number & & \\
\hline Bonus for work experience & Number & & \\
\hline Advance on salary & Number & & \\
\hline
\end{tabular}

\section{The PROGRAM Table}

\begin{tabular}{|l|l|l|l|l|}
\hline Attribute & Type & $\begin{array}{l}\text { Uni } \\
\text {-que }\end{array}$ & $\begin{array}{l}\text { Ref. } \\
\text { Integrity }\end{array}$ & Values \\
\hline $\begin{array}{l}\text { Hall } \\
\text { number }\end{array}$ & Number & & & $\begin{array}{l}\text { Between 100 } \\
\text { and 1000 }\end{array}$ \\
\hline $\begin{array}{l}\text { Doctor_ } \\
\text { ID }\end{array}$ & Number & & & \\
\hline $\begin{array}{l}\text { Assistant } \\
\text { ID }\end{array}$ & Number & Yes & Yes & \\
\hline $\begin{array}{l}\text { Day 1 } \\
\text { Schedule } \\
1\end{array}$ & $\begin{array}{l}\text { Short } \\
\text { Text }\end{array}$ & & & Between 18 and 20 \\
\hline Day 2 & $\begin{array}{l}\text { Short } \\
\text { Text }\end{array}$ & & & \\
\hline $\begin{array}{l}\text { Schedule } \\
2\end{array}$ & $\begin{array}{l}\text { Short } \\
\text { Text }\end{array}$ & & & Between 8 and 12 \\
\hline
\end{tabular}

The SPECIFIC_HALL Table

\begin{tabular}{|l|l|l|l|}
\hline Attribute & Type & Unique & Referential Integrity \\
\hline Hall number & Number & Yes & Yes \\
\hline Specific & Short Text & & \\
\hline Floor & Number & & \\
\hline Inside & Short Text & & \\
\hline $\begin{array}{l}\text { Number of } \\
\text { beds }\end{array}$ & Number & & \\
\hline Size & Number & & \\
\hline
\end{tabular}

The PATIENT Table

\begin{tabular}{|l|l|l|l|}
\hline Attribute & Tip & $\begin{array}{l}\text { Uni- } \\
\text { que }\end{array}$ & Required \\
\hline Hall number & Number & & No \\
\hline SSN & Number & Yes & \\
\hline Patient's first_name & Short Text & & \\
\hline Patient's last_name & Short Text & & \\
\hline Sex & Short Text & & \\
\hline
\end{tabular}




\begin{tabular}{|l|l|l|l|}
\hline Treatment & Number & & \\
\hline Chronically_disease & Short Text & & \\
\hline Improvement & Yes/No & & \\
\hline
\end{tabular}

The TREATMENT table

\begin{tabular}{|l|l|l|l|l|}
\hline Attribute & Type & $\begin{array}{l}\text { Uni- } \\
\text { que }\end{array}$ & $\begin{array}{l}\text { Req } \\
\text { uired }\end{array}$ & $\begin{array}{l}\text { Referential } \\
\text { Integrity }\end{array}$ \\
\hline Treatment ID & Number & Yes & Yes & Yes \\
\hline Diagnosis & Short Text & & & \\
\hline Pills & Short Text & & & \\
\hline Days & Number & & & \\
\hline Health & Short Text & & & \\
\hline Improvement & Yes/No & & & \\
\hline
\end{tabular}

\section{Relational data model development}

The relational database schema is the step in which we build the tables, columns and relationships that make uparelational database. Determining a key for a relation is an important aspect of database design and it is us ed when we selectaprimary index structure. Our application will have the following schema:

DOCTOR (doctor's name, doctor's surname, ID doctor, mobile phone, E-mail, ID_title, ID_coordinator, employment date, Status)

TITLE (ID title, Title, Basic Salary, age, work experience, Advance on salary)

PROGRAM (ID doctor, ID assistant, hall number, day1, schedule 1, day 2, schedule 2)

SPECIFC ROOM (hall room, Specific, Floor, Interior, number of beds, size_mp)

PATIENT (hall number, CNP, patient's name, patient's surname, gender, chronic diseases, treatment, improvment)

TREATMENT (ID treatment, Diagnosis, Drugs, days, health)

\section{Define the data integrity constraints}

There are three types of structural constraints (key, reference and the entity) constituting the minimal set of rules of integrity that they must have a relational database. Integrity minimal restrictions are defined in relation to the notion of key relationships and these must be reflected in the cloud database design. In our model structural constraints are:

R1: The ID_Doctor and the ID_Title are the composite primarykey in the Doctor table

R2: ID_Title is the primarykey in the table TITLE

R3: ID_Doctor and ID_Assistant are the composite primarykey in the table PROGRAM

R4: Hall_No is the primary key in table SPECIFIC HALL.

R5: SSN is the primarykey in table PATIENT.

R6: ID_Treatment is the primarykey in table TREATMENT

R7: All foreign keys values mustbe found in the values of the primarykey of the tables that are in relationship

The domain of our relationship has to fit certain values. Domain restrictions in our model are:

R20: Hall_No has values between 100 and 1000

R21: The Schedule 2 is between 8 and 12

R22: The Schedule 1 is between 16 and 20

\section{USING SQL AS QUERY LANGUAGE FOR OUR DATABASE}

$S Q L$ is a veryimportant database service for applications built in the cloud that makes it easyto set-up, maintain, manage and administer our relational database in the cloud[21]. In the same time is very easy to use and can obtain important results.

As an example we build a pivot table for our database and the code for our query is written below.

TRANSFORM Count (Patient.SSN) AS CountofSSN

SELECT Patient. Sex 
FROM Patient

GROUP BY Patient.Sex

PIVOT Patient.Hall_no;

The result, applied on our table is the patients, divided by sex and by number of the hall:

\begin{tabular}{|c|c|c|c|c|c|c|c|c|c|c|c|c|c|}
\hline \multicolumn{14}{|c|}{ 1.2Patent pocen sex } \\
\hline Ser & - & 191 & • & 102 & - & 201 & 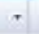 & 202 & - & 321 & - & 302 & - \\
\hline i & & & 1 & & & & 1 & & 1 & & 1 & & \\
\hline M & & & 1 & & 2 & & & & I & & 1 & & 1 \\
\hline
\end{tabular}

Fig. 5. The patients, divided by criterias, example of a pivot table

We may use any built-in function of SQL or we can create a user-defined function. For example we write a query which determines experience of doctors, measured in years.

SELECT Doctors.Id_doctor, Title.Title, Year(Now ()) Year([Emplyment_dāte]) AS Vechime

FROM Title INNER JOIN Doctors ON Title.Id_title =

Doctor.Id_title;

All facilities of SQL functions can be used in all situations when we meet values, rows, columns or tables. In the same time all this features can be used in constraints, calculated columns, joins, in WHILE or HAVING clause, or in other functions. They become the most relevant part of SQL and can be im plemented with great success in cloud.

For example let's take into consideration another question: Which are the patients with chronicallydisease? The answer of this question can be obtaine with the following SQL phrase.

SELECT Patient.Firstname, Patient.Lastname, Patient.Chronic disease, IIf(IsNull([Chronic_disease]), "NO","YES") AS Chronic_ill FROMM Patient; The result is shown in the picture below.

\begin{tabular}{|l|l|l|l|}
\hline Sabau & Bogdan & Parkinson & DA \\
\hline Luca & Florin & Hipertensiune, Alzheimer & DA \\
\hline Hadarau & Rares & Hipertensiune & DA \\
\hline Salagean & Rares & & NU \\
\hline Popescu & George & Astm & DA \\
\hline Lupescu & Dorin & Cancer pulmonar & DA \\
\hline Albu & lulia & Diabet, Artrita & NU \\
\hline Moldovan & Ana & Anemie & DA \\
\hline Pop & Paula & & DA \\
\hline Cotoi & Gabriela & NU \\
\hline
\end{tabular}

Fig. 6. The result of a query which determines the patients with chronically disease

The distribution of the treatments can be made with the help of next query.

SELECT Patient.First_name, Treatment.Diagnostic, Treatment.ID_treatment

FROM Treatment INNER JOIN Patient ON Treatment.ID treatment = Pacient.Treatment;

The result is a view like in the picture below. The columns are:Patient_Name, Diagnostic and Id_treatment.

\begin{tabular}{|l|l|r|}
\hline Salagean & Diabet & 1 \\
\hline Moldovan & Diabet & 1 \\
\hline Luca & Hipertensiune & 2 \\
\hline Hadarau & Hipertensiune & 2 \\
\hline Cotoi & Artrita & 3 \\
\hline Lupescu & Cancer pulmor & 4 \\
\hline Popescu & Astm & 5 \\
\hline Sabau & Parkinson & 6 \\
\hline
\end{tabular}

Fig. 7. The result of a query which determines the distribution of the treatments

The list of recovered patients we can obtain it with the following query.

SELECT Patient. Name, Treatment.Diagnostic 
I NTERNATIONAL JOURNAL OF COMPUTERS \& TECHNOLOGY

FROM Treatment INNER JOIN Patient ON Treatment.ID_treatament = Patient. Treatament

WHERE [Treatment]! [Improvement] =0;

The number of the patients of a room can be obtain using specific function as we see below.

SELECT [Specific_room].Hall_no, Count(Pacient.Nume_pacient) AS CountofNume_pacient

FROM [Specific room] INNER JOIN Patient ON [Specific room].Hall_no = Patient.Hall_no

GROUP BY [Specific room]. Hall_No;

Persons employed after 2000 year we can find the following statement SELECT.

SELECT Doctor.Doctor_Firstname, Doctor.Doctor_Lastname, Doctor.Emplyoment_day

FROM Doctor

GROUP BY Doctor. Doctor_Firstname, Doctor.Doctor_Lastname, Doctor.Emplyoment_day

HAVING ( ( (Doctor.Emplyoment_day) >DateSerial $(2000,1,1)$ Or (Doctor.Emplyoment_day) =\#1/3/200\#));

\begin{tabular}{||l|l|r|}
\hline Campean & Laura & $12 / 3 / 2007$ \\
\hline Gherman & Lia & $10 / 1 / 2007$ \\
\hline Mailat & Loredana & $10 / 12 / 2000$ \\
\hline Petrescu & Silviu & $12 / 3 / 2001$ \\
\hline Pop & Luciana & $8 / 20 / 2001$ \\
\hline Popovici & Aurelian & $12 / 3 / 2009$ \\
\hline Vultur & Lavinia & $4 / 13 / 2001$ \\
\hline
\end{tabular}

Fig. 8. Persons employed after 2000 year

The number of patients on a floor can be obtain with the following query.

SELECT [Specific Hall].Floor, Count(Patient.Patient_Name) AS CountofPatient_Name

FROM [Specific Hall INNER JOIN Patient ON [Specific Hall].Hall_No= Patient. Hall_ No

GROUP BY [Specific Hall.Floor;

The result is:

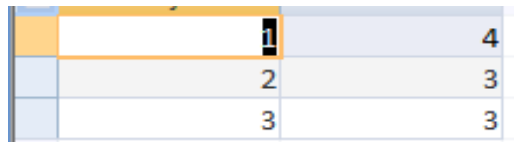

Fig. 9 The number of patients on a floor

The number of patients on a room is calculated with the help of following query, and the result in the figure below.

SELECT Patient.Hall_No, Count(Patient.Hall_No) AS Total_patients

FROM Patients GROUP BY Patient.Hall_No;

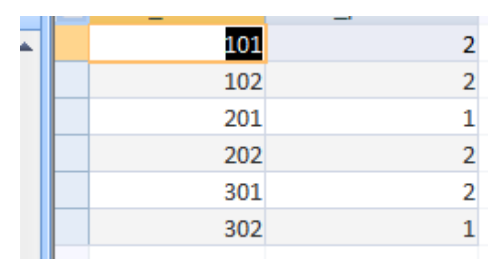

Fig. 10. The number of patients on a room 


\section{CONCLUSIONS}

Rapid changes made recentlyswept across the globe, the transition from information society to knowledge so ciety has major implications affecting all as pects of human life, all organizations and management approaches in today's society.

Information with all its essential aspects from production and transfer to the integration and exploitation constitutes in the present the principal source of the competitive advantage of any organization. Hence, we remark the growing interest for information, from its appearance, access and to the accurately information management.

The authors of this paper wanted to build a database to be SQL-based and use relational model for specialized medicine. The benefits of the design of such application could be: improving the working times and improving medical decisions, accessibility regardless of location or computer. Another advantage would be the information safety by using permanent backup of data, and the integration with CNAS solutions - The SIUI reports are automaticallygenerated and the solution is integrated with the National Electronic Prescription System.

Not ultimately we underline the ease of maintenance, updates as a result of legislative changes and maintenance of nomenclatures (services, medication lists, procedures, etc.), all being made by the supplier in real time.

\section{ACKNOWLEDGEMENT}

The present research was supported by the PNII-RU-TE-2014-4-2640 UEFISCDI grant "eTrajectory-students' professional trajectory".

\section{REFERENCES}

[1]. What is cloud computing? https://www.ibm.com/cloud-computing/what-is-cloud-computing (2016)

[2]. Cloud Computing Application, www.datev.de/Cloud (2016)

[3]. Sorofman, J.: The Cloud Computing Adoption Model, http://www.drdobbs.com/web-development/ the-cloudcomputing-adoption-model/211201818 (2008)

[4]. Sorofman, J.: How to Achieve the Strategic Value of Cloud while Delivering Real ROI

$\mathrm{http}: / / w w w . e w e e k . c o m / c / a / C l o u d-C o m p u t i n g / H o w-t o-A c h i e v e-t h e-S t r a t e g i c-V a l u e-o f-C l o u d-w h i l e-D e l i v e r i n g-R e a l-R O I$ (2009)

[5]. 10 Great Cloud Apps and Services for Small Business, http:/www.salesforce.com/uk/ socialsuccess/cloudcomputing/10-great-cloud-applications-services-smes.jsp (2016)

[6]. Butler, B.: 10 of the most useful cloud databases, http://www.networkworld.com/ article/2162274/cloudstorage/cloud-computing-10-of-the-most-useful-cloud-databases.html (2016)

[7]. Windows Azzure, http://fmi.unibuc.ro/msp/2012/04/01/laboratoare-de-windows-azure/ (2012)

[8]. Beal, V.: http://www.webopedia.com/TERMC/cloud_database.html (2016)

[9]. Building Oracle Database Applications in the Cloud, https://cloud.oracle.com/database (2016)

[10].Cloud Computing and Databases: Technology to Improve Database Management, http://study.com/academy/lesson/cloud-computing-and-databases-technology-to-improve-databasemanagement.html (2016)

[11].Oracle Database Cloud Service, http://www.oracle.com/us/database-cloud-service-wp-1844123.pdf (2012)

[12].David Linthicum, SQL and relational databases: They're not right for the cloud, http://www.infoworld.com/article/2628552/cloud-computing/sql-and-relational-databases--they-re-not-right-for-thecloud.html (2010)

[13].Abolfazli, S., Sanaei, Z. et al.: Cloud-Based Augmentation for Mobile Devices: Motivation, Taxonomies, and Open Challenges, IEEE Communications Surveys and Tutorials, Volume 16, Issue 1, Pages:337 - 368, ISSN: 1553-877X, IEEE Communications Society Press, USA, (2014).

[14].Joarder, K. et al.: Workload-Aware Incremental Repartitioning of Shared-Nothing Distributed Databases for Scalable OLTP Applications, Future Generation Computer Systems (FGCS), Volume 56, Pages: 421-435, ISSN: 0167-739X, Elsevier Science (2016).

[15].Joarder, K. et al.: Workload-Aware Incremental Repartitioning of Shared-Nothing Distributed Databases for Scalable Cloud Applications, Proceedings of the 7th IEEE/ACM International Conferencce on Utility and Cloud Computing (UCC 2014, IEEE CS Press, USA), ( 2014).

[16].NIST Cloud Computing Program, http://www.nist.gov/it//cloud/index.cfm (2016)

[17].Cloud Computing Applications Collections You Can Try, http://mobilecloudtechnology.blogspot.ro/2016/05/cloudcomputing-applications.html (2015)

[18].Cloud Applications, http://www.micron-soft.com/cloud\%20 application.htm (2016) 
I NTERNATIONAL JOURNAL OF COMPUTERS \& TECHNOLOGY

[19].Cloud Database, http://searchcloudapplications.techtarget.com/definition/cloud-database-database-as-a-service (2016)

[20].Divyakant, A., Amr, A., Suan, W.: Secure and Privacy-Preserving Data Services in the Cloud: A Data Centric View, http://vldb.org/pvldb/vol5/p2028 divakantagrawal vldb2012.pdf, (2016)

[21]. Cloud SQL, Second Generation, https://cloud.google.com/sql/ (2016)

[22].Gelogo, I., Lee, S: Database Management System as a Cloud Service, International Journal of Future Generation Communication and Networking Vol. 5, No. 2 (2012) 